\title{
Learning Strategies in Online Collaborative Examinations
}

\author{
- Jia Shen, Starr Roxanne Hiltz, and Michael Bieber
}

\begin{abstract}
New forms of computer-mediated, online learning can benefit from new forms of assessment that fit the medium and the pedagogical style of the online environment. This paper investigates students' learning styles and learning strategies in taking online collaborative exams. Applying constructivist and collaborative learning theories, the collaborative examination features students' active participation in various phases of the exam process through small group activities online. Students' learning strategies, including deep learning and collaborative learning, are investigated using a $1 \times 3$ field quasi-experiment to compare the team-based collaborative online exam with the traditional in-class exam and with the participatory exam, where students participate in the online exam processes individually. Data analysis using results from 485 students indicates that collaborative examinations significantly reduced surface learning in exam study, enhanced interactions and the sense of an online learning community, and increased perceived learning. The results also suggest learning predispositions were significantly correlated with exam study strategies, and provide indications of their effects on learning strategies.
\end{abstract}

Index Terms-Collaborative examinations, collaborative learning, deep learning, online learning, peer assessment, surface learning.

ith over three million university students taking online courses in the US alone in 2005, and with online education becoming part of the long-term strategy for many schools [1], enhancements to the online learning process take on practical as well as theoretical importance. Most current published studies focus on learning outcomes only, such as satisfaction and learning. Prominent researchers such as Alavi and Leidner, however, have called for more depth and breadth in the empirical studies in online learning [2], and Hiltz and Goldman have proposed comprehensive input-process-output models to guide research on the interaction of the many variables that influence the effectiveness of asynchronous learning networks (ALN) [3]. Benbunan-Fich and Hiltz, for example, examined mediators of the effectiveness of online courses, and found that motivation and active participation, among other variables, significantly mediated learning results [4]. Thus, there is an increasing need to examine other variables such as students' learning predispositions and learning strategies in order to provide a better understanding of online learning.

Manuscript received February 15, 2006;

revised August 30, 2006.

$\mathrm{J}$. Shen is with the Department of Computer and Information Systems, College of Business Administration, Rider University, Lawrenceville, NJ 08648-3099 USA (email: jiashen@rider.edu). S. R. Hiltz and M. Bieber are with the Information Systems Department, New Jersey Institute of Technology, University Heights, Newark, NJ 07102-1982 USA (e-mail: hiltz@njit.edu; bieber@njit.edu).

Color versions of one or more of the figures in this paper are available online at http://ieeexplore.ieee.org.

IEEE 10.1109/TPC.2007.2000053
Our research aims at a deep investigation of students' learning dispositions, strategies, and outcomes in the context of online exams. Students not only should be evaluated by, but should also learn through assessment. The traditional instructor-controlled exam reflects the objectivist learning model [5], which regards learning as the uncritical transfer of objective knowledge from instructor to students. New assessment approaches based on constructivism theory [6] propose that learners actually construct knowledge, guided by their own ideas and interests. Instead of presenting learners with information perhaps unrelated to their own ways of thinking, constructivist approaches emphasize the role prior knowledge plays in building new knowledge [7]. For example, learner-centered assessment [8] and classroom assessment [9] shift attention from instructors and teaching to students and learning through assessment.

COLlaBORATIVE LEARNING, an offspring of the constructivist model, is a learner-centered and team-oriented approach that assumes learning emerges as learners interact with each other [10]. Studies have shown the superiority of collaborative learning in both face-to-face settings and online education using group support systems (GSS) [3], [11].

Despite the collaborative learning paradigm that dominates ALN, only a few studies have been conducted to incorporate students' active participation and collaboration into the assessment process online. With the use of GSS, students' participation and collaboration have been integrated into specific phases of collaborative 
assessment, such as collaborative development of the grading scheme [12], question composition [13], collaborative question answering [14]-[16], and peer- and self-grading [17]-[19].

Incorporating constructivism and collaborative learning theories, the online exams in this study feature students' active participation in various phases of the exam process through small group activities. Students designed exam questions, answered questions designed by their peers, and graded answers to the questions they authored. In the online participatory exam, students participate in the online exam process individually. When overall positive results of the online participatory exam were revealed in previous studies [20], [21], the online collaborative exam was designed and examined in this study in the hope of further improving students' learning. The online collaborative exam features students working in small groups in the question design and grading phases, but individually in the answering phase. Although the most common form of collaborative testing refers to students providing a common set of exam answers [16], we believe question design and grading phases are important opportunities for students to learn, which can be further enhanced with group work. The answering phase remains individual to allow the exam to assess an individual student's learning.

A field experiment was conducted to evaluate the online exams compared with the traditional in-class exam. This paper examines students' learning styles and their adoption of learning strategies in taking online exams, in particular deep learning and collaborative learning, as well as student learning outcomes.

\section{Theoretical Context}

In contemporary educational theory, one influential group of researchers has identified learners' approaches to be either surface level or deep level [22]-[25]. A deep learning approach is consistent with a search for knowledge and understanding, whereas a surface learner is concerned only with passing exams by memorizing facts. Learning approaches have a motivation and a strategy element, which are related [22], [24]. Students attempt to understand a topic (deeply) if it is of real interest to them or if they can see its relevance to their current or future professional roles; whereas a surface approach is associated with limited interest in a task or an extrinsic motivation. While students normally have a predisposition to either deep or surface approaches in general, this preferred approach can be modified by the teaching context or learning environment for individual courses or particular learning tasks. Measures of approaches to learning can, therefore, be related to aspects of the teaching and learning environment. In assessment, prior studies have found that among other variables, students dynamically form exam study strategies according to different assessment methods, while their predisposition towards a surface or deep learning approach also impacts their exam studying strategies [26], [27].

Collaborative learning has been identified as essential for creating an effective online learning environment [3]. Collaborative learning involves social (interpersonal) processes by which a small group of students work together (i.e., collaborate and work as a team) to complete an academic problem-solving task designed to promote learning. Many theories that are distinctively social have been advanced, such as situated learning [28], distributed cognition [29], and learning communities [30]. Applying these social learning theories to the online environment, online researchers have studied the capacity of the online environment to support social activities and interaction [31]-[33]. They found that the extent of students' perceptions of their learning experiences online as actively involving, socially rich, and collaborative can improve their learning outcomes.

\section{Research Model and Hypotheses}

Fig. 1 shows the research model that will be discussed in this paper. This is part of a larger research framework [34] developed based on the Online Interaction Learning Model [35].

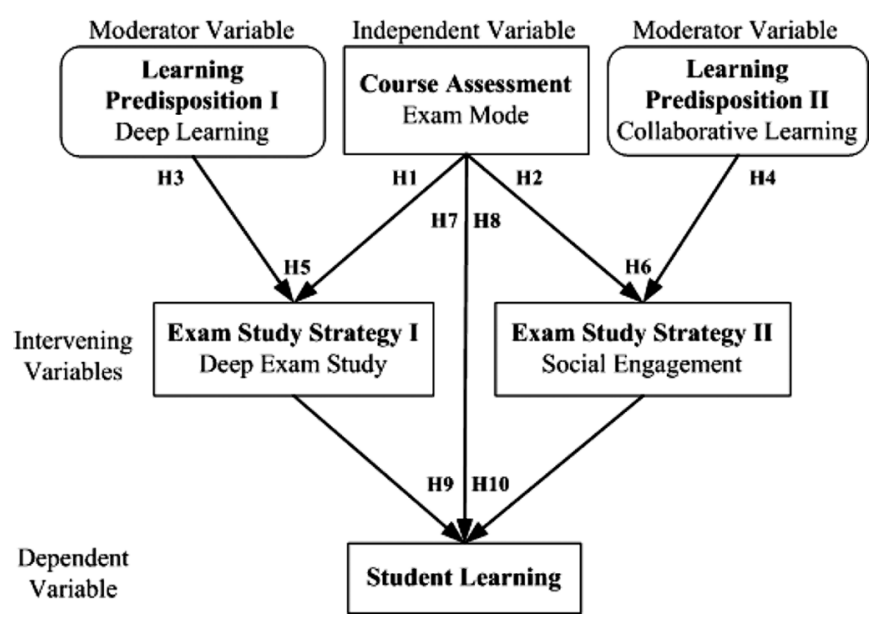

Fig. 1. Research model. 
Exam Modes The independent variable consists of three exam modes: the traditional exam, the participatory exam, and the collaborative exam. Fig. 2 compares and contrasts the three exam processes as they were conducted in this study.

In both the participatory exam and the collaborative exam, the process of involving students in question design and grading is conducted online. While students in the participatory exam perform these steps individually, students in the collaborative exam first participate individually (i.e., each designs questions and grades), and then the group (of three to five students) as a whole discusses, improves, and reaches consensus on the questions and grades. Typically, essay type questions are designed and answered by students. As discussed above, students answer exam questions individually in all three exam modes to maintain the exam's ability to provide accountability of individuals' learning.

Learning Predispositions Many studies in web-based learning have indicated that student characteristics [36], among other contextual factors [37], are likely to influence learning. As part of student characteristics, students' predispositions on learning are expected to moderate the strategies they adopt. In particular, the following two aspects of students' learning predispositions are examined

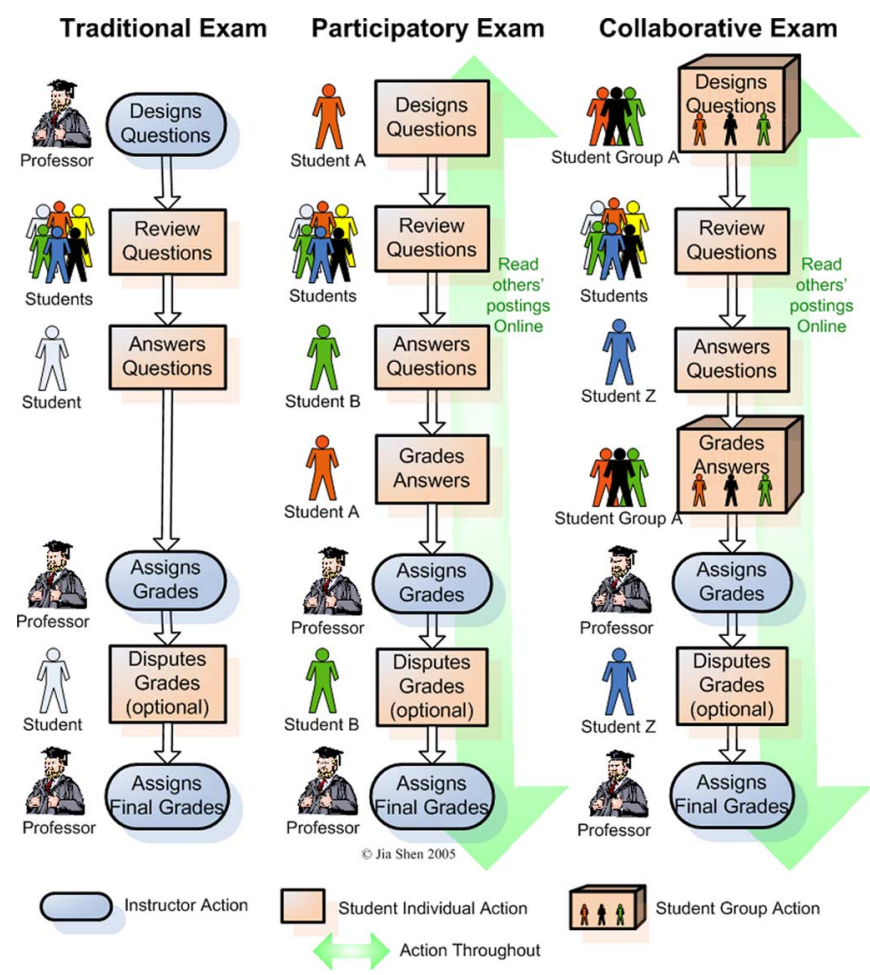

Fig. 2. Comparison of the three exam modes. in this study: (1) deep learning, and (2) collaborative learning.

As discussed previously, DEEP LEARNING is a student's approach to learning which is consistent with a search for knowledge and understanding; whereas a surface approach is concerned only with passing exams by memorizing facts. Studies have shown that students normally have a predisposition to either deep or surface learning. In this study, students' deep learning predisposition was measured before the exam through questions about their approaches to learning the course materials.

Collaborative learning predisposition is developed in this study to describe students' orientations in using collaborative learning strategies and learning from other students. A COLLABORATIVE LEARNING APPROACH is consistent with learning from interacting with other students and enjoying working with other students. As with deep learning, students' collaborative learning predispositions were measured before the exam.

Exam Study Strategies The exam study process includes the learning activities that occur in preparing for and participating in an exam. In the traditional exam, the exam study process includes preparation before the exam, learning while answering questions during an exam, and reviewing the instructor's feedback after the exam. In the participatory and collaborative exams, the exam study process includes not only the activities associated with the traditional exam, but also additional activities during the question design phase, the grading phase, and review of others' postings in the ALN environment.

While deep learning is associated with students' general learning approach to the course, deep exam study is associated with the specific learning strategies students adopt in exam study. DEEP EXAM STUDY is defined in this study as the extent of the student's search for knowledge and understanding during the exam studying process. Low adoption of deep exam study (i.e., surface exam study) is associated with passing exams by memorizing facts, while high adoption of deep exam study is associated with seeking knowledge and understanding. Deep exam study is reflected in a number of strategies the student may use in exam studying, such as adopting professional perspectives to understand course materials, and spending extra time to obtain more information on interesting topics [26], [27]. In this study, deep exam study was measured after the exam through 
questions about the specific approaches students adopted.

Similarly, social engagement is associated with the specific learning strategies students adopt in exam study. SOCIAL ENGAGEMENT is defined as the extent of a student's active involvement in learning from other students through the exam study process, and the sense of forming a learning community. High adoption of social engagement in exam studying is using strategies such as getting to know other students better through the exam process, acknowledging learning from others, and forming a learning community.

Student Learning Student learning outcomes are examined from two perspectives in this study: student perceived learning, and actual learning. Perceived learning was measured using 12 items in the post-exam surveys. Among the 12 items, 10 were designed based on Bloom's taxonomy [38] to measure perceived learning from lower levels, such as understanding the materials, to higher levels, such as comprehension, understanding, application, analysis, synthesizing, and evaluation. The other two items were adapted from the collaborative exam questionnaire used in previous studies conducted by the authors [21], [39].

Actual learning was measured using exam grades in final exams whenever possible, where the experiment was conducted during the midterm and a conventional exam was given as the final exam. In those courses where there are no final exams but final projects instead, the final project grades were used as a measure of actual learning.

\section{Research Questions and Hypotheses Since} the collaborative exam is the main innovation of this research and thus the focus of the paper, the following hypotheses compare the collaborative with the participatory exam, and the collaborative with the traditional exam. For comparison of the participatory and traditional exam, see other publications [20].

Based on constructivism and collaborative learning theories, actively engaging students in the entire exam process as online collaborative groups should enhance learning and the sense of a learning community. Thus it was hypothesized that students in the collaborative exam would adopt higher levels of deep exam study (H1) and higher levels of social engagement (H2) than students in the other two exam modes. In addition, students in the collaborative exam would achieve better learning outcomes, including perceived learning (H7) and actual learning as measured using final exam or project grades (H8). As students' predispositions towards a surface or a deep learning approach also affect their exam studying strategy, it is hypothesized that students' predispositions on deep learning or collaborative learning will affect their adoption of deep learning (H3) or social engagement (H4) in exam studying. The interaction effects of exam modes and learning predispositions (H5, H6), and exam modes and exam study strategies (H9, H10) are also investigated. While previous studies on online examinations indicate overall positive results, student interviews suggest that there may be a wider range of exam strategies adopted in taking the online exam compared with the traditional exam [20], [21], [40], [41]. The research questions and hypotheses are listed below, with corresponding hypothesis numbers shown in the research model in Fig. 1.

RQ1: Do students adopt different exam study strategies in the collaborative exam mode than the other two exam modes?

H1: Students taking the collaborative examination will have higher adoption of deep learning in the exam studying process than students taking the traditional exam (H1.1) or the participatory exam (H1.2). H2: Students taking the collaborative examination will have higher social engagement in the exam studying process than students taking the traditional exam (H2.1) or the participatory exam (H2.2).

RQ2: Do students' exam study strategies correlate to their learning predispositions?

H3: Students' adoption of deep learning in the exam studying process will be positively related to their predispositions to deep learning.

H4: Students' level of social engagement in the exam studying process will be positively related to their predispositions to collaborative learning.

RQ3: Do the relationships between students' learning predispositions and their exam study strategies differ in the collaborative exam and the traditional exam?

H5: The difference in the adoption of deep exam study between students who are the least deep-oriented and those who are the most deep-oriented will be larger in the collaborative exam than in the traditional exam.

H6: The difference in the adoption of social engagement in exam studying 
between students who are the least collaborative-oriented and the most collaborative-oriented will be larger in the collaborative exam than in the traditional exam.

RQ4: Do students achieve better learning in the collaborative exam than the other two exam modes?

H7: Students taking the collaborative examination will have higher perceptions of learning than students taking the traditional exam (H7.1) or the participatory exam (H7.2).

H8: Students taking the collaborative examination will achieve higher grades in the final exam/projects than students taking the traditional exam (H8.1) or the participatory exam (H8.2).

RQ5: Do the relationships between students' exam study strategies and perceived learning differ in the collaborative exam and the traditional exam?

H9: The difference in perceived learning between students who adopt the least deep learning and the most deep learning in exam study will be higher in the collaborative exam than in the traditional exam.

H10: The difference in perceived learning between students who are most socially engaged and those who are least engaged in exam study will be higher in the collaborative exam than in the traditional exam.

\section{Research Design}

Subjects To investigate the research questions, a $1 \times 3$ quasi-experimental nonequivalent groups design with pre- and post-measures was employed. This is appropriate given the situation of the study where the participants were aggregated into groups (i.e., course sections) for educational purposes, and where random assignment was not possible. The study was conducted in the spring, summer, and fall semesters of 2004 at a US university. A total of 22 course sections at the undergraduate and graduate levels participated in the experiment. A balancing technique was used to assign sections with similar characteristics to different exam modes in order to counterbalance pre-existing differences among students.

Table I shows the number of subjects in each condition and the response ratio. Extra credit towards the exam grade was provided as incentive to complete the surveys.

Procedures Detailed exam instructions including question design and answer grading criteria were provided to students before the exam. The entire online exam took about two and a half weeks, including about three days for each of the main phases: question design, answering, and grading, and a few days for the instructor's activities, such as question review and assignment. The online exams were conducted using WebBoard and WebCT, and the process was anonymous using pen names. Students in the traditional exam condition took the exam in class, or through proctors in remote sites in distance-learning courses. The instructor provided the questions and graded students' answers. With the instructors' permissions, students were allowed to use certain course materials in the traditional exams in this study, such as course notes, books, or other references, in order to make the exam conditions comparable in this regard. Grading criteria and guidelines equivalent to those of the online exams were provided in advance of the exam to students. Questions of similar types (e.g., essay) were asked in matching course sections in different exam modes whenever possible (e.g., because of a matching section in the same semester, questions designed by students in the online section were re-used for the traditional exam in the same course.)

Students in all three conditions filled out the pre-exam questionnaire regarding demographics and learning predispositions. Shortly following the exam, students were asked to complete the post-exam questionnaires, which have many of the same questions for the three conditions to allow comparison. The questionnaires adapted items that have been validated [26], [42], and items from

TABLE I

$1 \times 3$ FiEld EXPERIMENT AND NuMBER OF SubJECTS

\begin{tabular}{|c|c|c|c|c|}
\hline & \multicolumn{3}{|c|}{ Exam Mode } & \multirow[b]{2}{*}{ Total } \\
\hline & 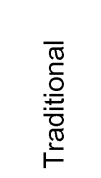 & $\begin{array}{l}\frac{7}{0} \\
\frac{0}{\pi} \\
\frac{0}{0} \\
\frac{0}{0} \\
\frac{\pi}{0} \\
0\end{array}$ & $\begin{array}{l}\stackrel{D}{D} \\
\stackrel{0}{0} \\
\frac{0}{0} \\
\frac{0}{0} \\
\overline{0}\end{array}$ & \\
\hline $\begin{array}{l}\text { Experimental } \\
\text { subjects }\end{array}$ & 235 & 152 & 199 & 586 \\
\hline $\begin{array}{l}\text { Survey } \\
\text { subjects }\end{array}$ & 173 & 137 & 175 & 485 \\
\hline Return rate & $73.6 \%$ & $90.1 \%$ & $87.9 \%$ & $83 \%$ \\
\hline
\end{tabular}


previous studies on the online exam [21], [39] with revisions and additions. The questions used are shown in the results section of this paper.

\section{Collaboration Support Systems Used in}

the Study WebBoard and WebCT were the asynchronous conferencing systems used to facilitate the participatory and the collaborative exams in this study. Both systems have "conferences," which are threaded discussion areas where students can post, read, and reply to comments of others. One main conference was created for the main exam activities; administration information and student feedback were posted in general administration and feedback conferences.

\section{FINDINGS}

The raw data were analyzed using SPSS. This section first presents the factor analysis and normalization test results, followed by item-level response analysis, and finally hypothesis testing outcomes.

\section{Factor Analysis, Reliability of Scales, and Addition of Hypotheses Through principle} component factor analysis with PROMAX rotation, the following three factors were extracted from the pre-exam questionnaire:

(1) Deep learning: 5 items, Chronbach's alpha = 0.83 .

(2) Surface learning: 5 items, Chronbach's alpha = 0.78 .

(3) Collaborative learning: 7 items, Chronbach's alpha $=0.87$.

Items measuring the deep learning predisposition construct split into two factors. The positive items converged into one factor (deep learning), and the negative items converged into another factor (surface learning). The items measuring collaborative learning converged into one factor as expected.

Using a similar procedure, the following factors were extracted from the post-exam survey results.

(1) Deep exam study: 6 items, Chronbach's alpha $=0.80$.

(2) Surface exam study: 2 items, Chronbach's alpha $=0.70$.

(3) Social engagement: 4 items, Chronbach's alpha $=0.80$.

(4) Perceived learning: 12 items, Chronbach's alpha $=0.93$.

The items from the post-survey measuring the deep exam study construct split into two factors.
The positive items converged into one factor (termed deep exam study), and the negative items converged into another factor (termed surface exam study). The items measuring social engagement and perceived learning converged into factors as expected. These items are shown in Tables II and III.

The reliability analysis of the factors suggests the factors are highly reliable, with Chronbach's alpha all above the 0.7 level. The mean scores were calculated for all the factors, and the data were tested for normal distribution. Among the seven factors, four were normally distributed (deep learning, collaborative learning, deep exam study, and social engagement). Through data transformation, surface learning and perceived learning were successfully normalized. In addition, final exam/project grades were also tested for normal distribution, and they were normally distributed. In the next section, parametric data analysis was performed on factors that were normally distributed, and nonparametric data analysis was performed on surface exam study, which was not normally distributed.

Given deep learning splits into two factors (deep learning and surface learning) through the factor analysis above, $\mathrm{H} 1$ and $\mathrm{H} 3$ are each revised with an additional hypothesis addressing the new factor. Although deep exam study also splits into two factors, surface exam study factor is not normalized. Given the limitations of nonparametric tests, H5 and H9 are not revised, and only deep exam study is used in testing those hypotheses. The additional hypotheses are:

H1a: Students taking the collaborative examination will have lower adoption of surface learning in the exam studying process than students taking the traditional exam (H1a.1) or the participatory exam (H1a.2).

H3a: Students' adoption of surface learning in the exam studying process will be positively related to their predispositions in surface learning.

Before presenting the main results, it is necessary to point out that analysis using the pre-exam survey data shows no significant difference among students in the three exam modes before the exam. The one-way ANOVA comparing the learning dispositions revealed that there is no significant pre-existing differences of students among the three exam modes at the 0.05 level, including collaborative learning $F(2,417)=0.01 \cdot p=0.90$, deep learning $F(2,417)=2.52, p=0.08$, and surface 
learning $F(2,417)=0.832, p=0.44$. Students' demographic data were analyzed using Chi-Square tests, and no significant differences existed among the three conditions, including gender $\chi^{2}(2)=4.363$, $p=0.113$, work experience $\chi^{2}(10)=17.857, p=0.057$, and previous online exam experiences $\chi^{2}(6)=9.78$, $p=0.134$. This suggests the matching technique used in assigning courses to different exam modes was quite successful in preventing pre-existing differences among the three conditions.

Univariate Analysis This section presents key descriptive results from the post-exam survey on the individual question item level.

Deep Exam Study: Table II provides the univariate analysis results of the six items of the deep exam study factor, including means and standard deviations.

In five out of six items, students in the participatory or the collaborative exam reported adopting a deeper approach to exam study compared with

TABLE II

ITEMS MEASURING DEEP EXAM STUDY

\begin{tabular}{|c|c|c|c|}
\hline Item & 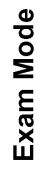 & 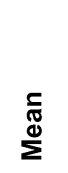 & ค \\
\hline \multirow{3}{*}{$\begin{array}{l}\text { When I was studying for the exam, I found } \\
\text { most topics interesting and spent extra time } \\
\text { trying to obtain more information about } \\
\text { them. }\end{array}$} & $T$ & 4.32 & 1.66 \\
\hline & $P$ & 4.68 & 1.55 \\
\hline & $C$ & 4.52 & 1.61 \\
\hline \multirow{3}{*}{$\begin{array}{l}\text { I found that I had to do enough work on a } \\
\text { topic so that I could form my own } \\
\text { conclusions before I was satisfied in } \\
\text { studying for the exam. }\end{array}$} & $T$ & 4.62 & 1.42 \\
\hline & $P$ & 4.85 & 1.35 \\
\hline & $C$ & 4.97 & 1.35 \\
\hline \multirow{3}{*}{$\begin{array}{l}\text { I tested myself on important topics until I } \\
\text { understood them completely while studying } \\
\text { for exam. }\end{array}$} & $T$ & 4.77 & 1.75 \\
\hline & $P$ & 4.22 & 1.71 \\
\hline & $C$ & 4.45 & 1.67 \\
\hline \multirow{3}{*}{$\begin{array}{l}\text { When I was studying for the exam, I put } \\
\text { myself in the position of a system analyst } \\
\text { and designer to try to understand his/her } \\
\text { role in organizations. }\end{array}$} & $T$ & 4.45 & 1.68 \\
\hline & $P$ & 4.78 & 1.52 \\
\hline & $C$ & 4.77 & 1.62 \\
\hline \multirow{3}{*}{$\begin{array}{l}\text { I spent a lot of time finding out more about } \\
\text { interesting topics which have been } \\
\text { discussed in this course when I was } \\
\text { studying for the exam. }\end{array}$} & $T$ & 4.01 & 1.71 \\
\hline & $P$ & 4.89 & 1.48 \\
\hline & $C$ & 4.66 & 1.65 \\
\hline \multirow{3}{*}{$\begin{array}{l}\text { When I was studying for the exam, I found } \\
\text { that I could relate this course's material to } \\
\text { other subject areas. }\end{array}$} & $T$ & 4.91 & 1.64 \\
\hline & $P$ & 5.28 & 1.47 \\
\hline & $C$ & 5.11 & 1.61 \\
\hline
\end{tabular}

$T$ : Traditional Exam; $P$ : Participatory Exam;

$C$ : Collaborative Exam. those in the traditional exam. For example, students in the participatory exam reported the highest adoption of deep exam study in terms of finding the topics interesting, being willing to spend extra time to study, adopting professional roles in understanding materials (e.g., putting oneself in the position of a system analyst and designer), spending extra time to find out additional information, and relating course materials to other subject areas. Students in the collaborative exam reported the highest level of achieving satisfaction by researching topics to form their own conclusions in exam study. The only item that had the highest score in the traditional exam is testing oneself on important topics until one understands them completely. The results suggest that students in the participatory and the collaborative exam adopted a deeper approach to exam study, including taking professional and academic perspectives in understanding materials, while students in the traditional exam tested themselves on important topics before the exams.

Surface Exam Study: Table III shows the results of the two items of the surface exam study factor. Note the negative items were converted back so that the item statement matches the mean (i.e., the higher the number, the more adoption of surface exam study).

For both items, students in the traditional exam adopted noticeably higher levels of surface study in their processing of information compared with those in the online exams, including trying to remember answers to likely questions as the best way to pass the exam ( $T=4.35, P=2.96, C=3.15)$, and learning by rote ( $T=3.94, P=2.89, C=3.00)$. Results suggest that students in the traditional

TABLE III

Items Measuring Surface EXam Study

\begin{tabular}{|c|c|c|c|}
\hline Item & $\begin{array}{l}\frac{0}{0} \\
\text { 0 } \\
\Sigma \\
\frac{E}{\tilde{x}} \\
\text { ய }\end{array}$ & 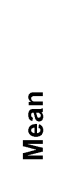 & 요 \\
\hline \multirow{3}{*}{$\begin{array}{l}\text { I found the best way to pass the exam I } \\
\text { participated in is to try to remember } \\
\text { answers to likely questions. }\end{array}$} & $T$ & 4.35 & 1.65 \\
\hline & $P$ & 2.96 & 1.75 \\
\hline & $C$ & 3.15 & 1.79 \\
\hline \multirow{3}{*}{$\begin{array}{l}\text { In studying for the exam, I learned most of } \\
\text { the things by rote, going over and over } \\
\text { them until I knew them by heart even if I } \\
\text { did not understand them. }\end{array}$} & $T$ & 3.94 & 1.75 \\
\hline & $P$ & 2.89 & 1.77 \\
\hline & $C$ & 3.00 & 1.86 \\
\hline
\end{tabular}

$T$ : Traditional Exam; $P$ : Participatory Exam;

$C$ : Collaborative Exam. 
exam had the highest adoption of surface exam study strategy in their processing of information.

Social Engagement: Table IV provides the results of the four items measuring the social engagement factor. For all four items, students in the collaborative online exam noticeably had the highest level of social engagement, including getting to know other students through the exam process ( $T=3.45, P=2.98, C=4.49$ ), perceiving the exam as a group process $(T=2.73, P=2.46$, $C=4.17$ ), forming a learning community through exam study ( $T=3.57, P=3.84, C=4.51)$, and enhancing understanding of course materials by interacting with other students $(T=3.80, P=3.81$, $C=4.46$ ). Results suggest that students in the collaborative exam had the highest adoption of social engagement in exam study. Interestingly, it is also noticeable that the level of social engagement in the participatory exam was lower than or as low as the traditional exam on most items. This suggests that without the small group activities, the level of social engagement in the online environment is as low as or even lower than the traditional settings.

Perceived Learning: Table $\mathrm{V}$ provides the results for the 12 items of the perceived learning construct.

In 10 out of the 12 items, students in the collaborative exam reported the highest level of

TABLE IV

ITEMS MEASURING SOCIAL ENGAGEMENT

\begin{tabular}{|c|c|c|c|}
\hline Item & 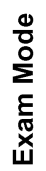 & $\stackrel{\substack{\mathbb{N} \\
\Sigma}}{\Sigma}$ & の \\
\hline \multirow{3}{*}{$\begin{array}{l}\text { I was able to get to know some students } \\
\text { better during the exam process. }\end{array}$} & $T$ & 3.45 & 1.93 \\
\hline & $P$ & 2.98 & 1.89 \\
\hline & $C$ & 4.49 & 1.88 \\
\hline \multirow{3}{*}{$\begin{array}{l}\text { The exam process was mainly a(n): } \\
\text { Individual (1) <-> Group Experience (7) }\end{array}$} & $T$ & 2.73 & 2.00 \\
\hline & $P$ & 2.46 & 1.84 \\
\hline & $C$ & 4.17 & 1.99 \\
\hline \multirow{3}{*}{$\begin{array}{l}\text { The exam allowed me to form a kind of } \\
\text { learning community with other students. }\end{array}$} & $T$ & 3.57 & 1.94 \\
\hline & $P$ & 3.84 & 1.96 \\
\hline & $C$ & 4.51 & 1.81 \\
\hline \multirow{3}{*}{$\begin{array}{l}\text { My understanding of course material was } \\
\text { enhanced by interacting with other } \\
\text { students in the class through the exam } \\
\text { process. }\end{array}$} & $T$ & 3.80 & 1.96 \\
\hline & $P$ & 3.81 & 1.96 \\
\hline & $C$ & 4.46 & 1.96 \\
\hline
\end{tabular}

$T$ : Traditional Exam; $P$ : Participatory Exam;

$C$ : Collaborative Exam. learning among the three exams. For the other two items, perceptions of students in the participatory

TABLE V

Items MeAsuring PERCEIVEd LEARNING

\begin{tabular}{|c|c|c|c|}
\hline Item & 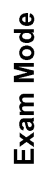 & $\underset{\substack{\pi \\
\mathbb{N}}}{\stackrel{5}{\Sigma}}$ & 이 \\
\hline \multirow{3}{*}{$\begin{array}{l}\text { My ability to judge the value of ideas } \\
\text { and assess the quality of arguments } \\
\text { has been improved through the exam. }\end{array}$} & $T$ & 4.46 & 1.52 \\
\hline & $P$ & 4.78 & 1.29 \\
\hline & $C$ & 4.91 & 1.45 \\
\hline \multirow{3}{*}{$\begin{array}{l}\text { My ability to use methods, concepts, } \\
\text { and theories I learned in this course in } \\
\text { new situations has been improved } \\
\text { through the exam. }\end{array}$} & $T$ & 4.71 & 1.53 \\
\hline & $P$ & 4.91 & 1.49 \\
\hline & $C$ & 4.97 & $\overline{1.50}$ \\
\hline \multirow{3}{*}{$\begin{array}{l}\text { My skill to compare and discriminate } \\
\text { between ideas has been improved } \\
\text { through the exam. }\end{array}$} & $T$ & 4.42 & 1.51 \\
\hline & $P$ & 4.56 & 1.35 \\
\hline & $C$ & 4.68 & 1.45 \\
\hline \multirow{3}{*}{$\begin{array}{l}\text { My ability to use course material to } \\
\text { make generalizations or predictions } \\
\text { has been improved through the exam. }\end{array}$} & $T$ & 4.51 & 1.48 \\
\hline & $P$ & 4.66 & 1.31 \\
\hline & $C$ & 4.86 & 1.52 \\
\hline \multirow{3}{*}{$\begin{array}{l}\text { I learned from answering the exam } \\
\text { questions. }\end{array}$} & $T$ & 4.64 & 1.62 \\
\hline & $P$ & 5.37 & 1.27 \\
\hline & $C$ & 5.44 & 1.42 \\
\hline \multirow{3}{*}{$\begin{array}{l}\text { My understanding of the meaning of } \\
\text { the course material was enhanced } \\
\text { through the exam. }\end{array}$} & $T$ & 4.77 & 1.54 \\
\hline & $P$ & 4.79 & 1.54 \\
\hline & $C$ & 4.89 & 1.55 \\
\hline \multirow{3}{*}{$\begin{array}{l}\text { I am better able to see different course } \\
\text { components and organize them in a } \\
\text { meaningful way through the exam. }\end{array}$} & $T$ & 4.18 & 1.58 \\
\hline & $P$ & 4.55 & 1.51 \\
\hline & $C$ & 4.50 & 1.46 \\
\hline \multirow{3}{*}{$\begin{array}{l}\text { My skill to relate knowledge from } \\
\text { several areas to make my argument } \\
\text { has been improved through the exam. }\end{array}$} & $T$ & 4.57 & 1.46 \\
\hline & $P$ & 4.84 & 1.41 \\
\hline & $C$ & 4.76 & 1.56 \\
\hline \multirow{3}{*}{$\begin{array}{l}\text { My ability to recognize patterns of } \\
\text { course material and their underlying } \\
\text { meanings has remained the same as } \\
\text { before exam. }{ }^{R}\end{array}$} & $T$ & 4.09 & 1.54 \\
\hline & $P$ & 4.03 & 1.49 \\
\hline & $C$ & 4.13 & 1.58 \\
\hline \multirow{3}{*}{$\begin{array}{l}\text { My ability to solve problems using what } \\
\text { I learned in this course has NOT been } \\
\text { improved through the exam. }{ }^{\text {R }}\end{array}$} & $T$ & 4.57 & 1.75 \\
\hline & $P$ & 4.84 & 1.59 \\
\hline & $C$ & 4.90 & 1.69 \\
\hline \multirow{3}{*}{$\begin{array}{l}\text { I learned from reading the exam } \\
\text { questions posted online. }\end{array}$} & $T$ & 4.38 & 1.86 \\
\hline & $P$ & 4.64 & 1.56 \\
\hline & $C$ & 4.77 & 1.46 \\
\hline \multirow{3}{*}{$\begin{array}{l}\text { My knowledge of major concepts, } \\
\text { methods, and theories has NOT been } \\
\text { improved through the exam. }{ }^{R}\end{array}$} & $T$ & 4.75 & 1.83 \\
\hline & $P$ & 5.18 & 1.70 \\
\hline & $C$ & 5.24 & 1.76 \\
\hline
\end{tabular}

$T$ : Traditional Exam; $P$ : Participatory Exam;

$C$ : Collaborative Exam. ${ }^{R}=$ reverse scored item. 
exam were the highest. For example, students in the collaborative exam reported the highest level of improvement in their knowledge of course concepts, methods and theories, and in their understanding of course materials. They also reported enhancement in skills such as using knowledge in new situations, solving problems, recognizing patterns, making generalizations and predictions, comparing and discriminating ideas, and making judgments and assessments of the quality of ideas and arguments. In addition, students in the collaborative exam reported the highest level of learning in reading exam questions posted online and in answering exam questions. Students in the participatory exam reported the highest level of improvement in seeing different course components and organizing them in a meaningful way, and relating knowledge from different academic areas. In 11 out of the 12 items, students in the traditional exam reported the lowest level of perceived learning among the three exams.

Hypothesis Testing To test the hypotheses, the mean scores were calculated for all the factors. To compare the differences among the three exam modes, one-way ANOVA tests were conducted on deep exam study and social engagement, which were normally distributed. The Kruskal Wallis test, which is the nonparametric equivalent of the one-way ANOVA, was conducted on surface exam study. The ANOVA results are shown in Table VI and the Kruskal Wallis test results are shown in Table VII, where the higher the mean rank, the higher the score.

Significant differences were found among the three exam modes in social engagement $(p<0.01)$ and surface exam study $(p<0.01)$, but not in deep exam study. Therefore, H1.1 and H1.2 are not supported.

TABLE VI

EXAM STUdy STRATEGIES (ANOVA TEST)

\begin{tabular}{|c|c|c|c|c|c|c|c|}
\hline 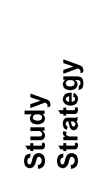 & $\begin{array}{l}\frac{0}{0} \\
\stackrel{0}{\Sigma} \\
\frac{\Sigma}{\mathbb{T}} \\
\mathbf{x}\end{array}$ & $\mathbf{z}$ & $\begin{array}{l}\frac{\Sigma}{\delta} \\
\sum \\
\sum\end{array}$ & $\begin{array}{l}0 \\
\text { c) }\end{array}$ & ч & 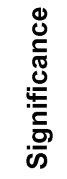 & 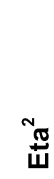 \\
\hline \multirow{3}{*}{ 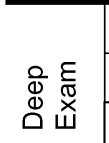 } & $T$ & 139 & 4.51 & 1.17 & \multirow{3}{*}{2.20} & \multirow{3}{*}{.112} & \multirow{3}{*}{.01} \\
\hline & $P$ & 110 & 4.78 & 1.00 & & & \\
\hline & $C$ & 137 & 4.74 & 1.18 & & & \\
\hline \multirow{3}{*}{ 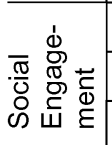 } & $T$ & 139 & 3.38 & 1.62 & \multirow{3}{*}{22.45} & \multirow{3}{*}{.000} & \multirow{3}{*}{.11} \\
\hline & $P$ & 110 & 3.27 & 1.45 & & & \\
\hline & $C$ & 136 & 4.41 & 1.43 & & & \\
\hline
\end{tabular}

$T$ : Traditional Exam; $P$ : Participatory Exam; $C$ : Collaborative Exam
Post-hoc analysis reveals that in terms of social engagement, students in the collaborative exam were significantly more engaged than students in the traditional $(p<0.01)$ and the participatory exams $(p<0.01)$. The effect size $\left(\right.$ eta $\left.^{2}\right)$ is weak (0.11), but both H2.1 and H2.2 are supported $(p<0.01)$. There is no post-hoc analysis for a Kruskal Wallis test. Two separate Mann-Whitney $U$ tests were conducted to compare the differences of surface exam study between the collaborative exam and the traditional exam, and between the collaborative exam and the participatory exam. Results show that students in the collaborative exam adopted significantly lower levels of surface exam study than students in the traditional exam $(p<0.01)$. Therefore, H1a. 1 is supported $(p<0.01)$, and H1a.2 is not supported.

To examine the relationship between students' deep/surface learning predispositions and their deep/surface exam study strategies, correlation analysis using Pearson's $r$ was conducted on deep exam study strategy. The Spearman's rho test was conducted on surface exam study. As shown in Table VIII, learning predispositions were significantly correlated with exam study strategies. Therefore, H3 is supported ( $r=0.55, p<0.01)$, and H3a is supported (Spearman's rho $=0.23, p<0.01$ ).

TABLE VII

EXAM Study Strategies (KRUSKal WALlis Test)

\begin{tabular}{|c|c|c|c|c|c|}
\hline 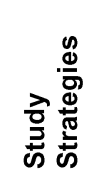 & 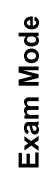 & $\mathbf{z}$ & 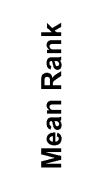 & 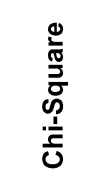 & 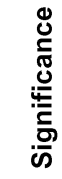 \\
\hline \multirow{3}{*}{$\begin{array}{l}\text { Surface } \\
\text { Exam }\end{array}$} & $T$ & 139 & 243.75 & \multirow{3}{*}{$45.02^{* *}$} & \multirow{3}{*}{.000} \\
\hline & $P$ & 110 & 159.55 & & \\
\hline & $C$ & 137 & 169.78 & & \\
\hline
\end{tabular}

$T$ : Traditional Exam; $P$ : Participatory Exam; $C$ : Collaborative Exam.

TABLE VIII

DeEp/Surface STUdy AND LEARNING PREDISPOSITIONS (CORRELATION)

\begin{tabular}{l|c|c}
\hline & Surface Exam $^{\text {a }}$ & Deep Exam \\
\hline $\begin{array}{l}\text { Pre-exam Surface } \\
\text { Learning }\end{array}$ & $.232^{* *}$ & $-0.424^{* *}$ \\
\hline $\begin{array}{l}\text { Pre-exam Deep } \\
\text { Learning }\end{array}$ & $-0.161^{* *}$ & $.549^{* *}$ \\
\hline
\end{tabular}

** Correlation is significant at the 0.01 level (2-tailed). ${ }^{a}$ Spearman's rho is used instead of Pearson's $r$ in this column. 
To examine the relationship between students' pre-exam collaborative learning and their social engagement in exam studying, a correlation analysis using Pearson's $r$ was conducted. Results show that the two variables were significantly correlated $(r=0.43, p<0.01)$. Therefore, $\mathrm{H} 4$ is supported.

To test H5, deep learning predisposition as measured by the pre-exam survey was first categorized into low, medium, and high. The two extreme categories were used and the medium category was excluded from further analysis. A 2 $\times 2$ factorial ANOVA test was then conducted to compare the two exam modes and the two deep learning predispositions. Tables IX and X show the means and the significance test results in factorial ANOVA. As shown in Fig. 3, the least deep-oriented students had a slightly larger increase in the level of deep exam study than those who were most deep-oriented (i.e., the slope of the diamond line is more steep than the square line). The interaction effect is not significant. Therefore, H5 is not supported. Though there is no relationship between exam mode and deep exam study, there is a moderately strong positive relationship between

TABLE IX

Deep Exam Study (EXAm Mode*PRe-EXAm Deep Learning)

\begin{tabular}{|c|c|c|c|}
\hline \multirow[b]{2}{*}{ 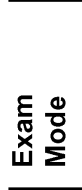 } & \multicolumn{2}{|c|}{$\begin{array}{l}\text { Pre-exam Learning } \\
\text { Disposition }\end{array}$} & \multirow[b]{2}{*}{ Total } \\
\hline & $\begin{array}{l}\text { Least Deep- } \\
\text { oriented }\end{array}$ & $\begin{array}{l}\text { Most Deep- } \\
\text { oriented }\end{array}$ & \\
\hline$T$ & $3.83(.96)$ & $5.29(1.17)$ & $4.47(1.28)$ \\
\hline$C$ & $4.11(1.16)$ & $5.32(1.09)$ & $4.75(1.27)$ \\
\hline Total & $3.95(1.05)$ & $5.31(1.12)$ & $4.60(1.28)$ \\
\hline
\end{tabular}

TABLE $X$

FACTORIAL ANOVA OF DATA From TABLE IX

\begin{tabular}{|c|c|c|c|c|c|}
\hline 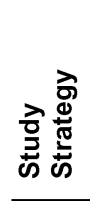 & \multicolumn{2}{|c|}{ Source } & ᄂ & 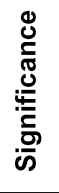 & 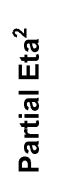 \\
\hline \multirow{3}{*}{$\begin{array}{l}\text { Deep } \\
\text { Exam }\end{array}$} & Main Effect & $\begin{array}{l}\text { Exam Mode } \\
(1,3)\end{array}$ & .800 & .373 & .005 \\
\hline & Main Effect & $\begin{array}{l}\text { Pre-exam } \\
\text { Deep } \\
\text { Learning }\end{array}$ & 59.677 & .000 & .277 \\
\hline & $\begin{array}{l}\text { Interaction } \\
\text { Effect }\end{array}$ & $\begin{array}{l}\text { Exam Mode* } \\
\text { Pre-Deep }\end{array}$ & .536 & .465 & .003 \\
\hline
\end{tabular}

pre-examination learning disposition and deep exam study, with an effect size of 0.277 .

To test H6, collaborative learning predisposition as measured by the pre-exam survey was first categorized into low, medium, and high. The two extreme categories were used, and a $2 \times 2$ factorial ANOVA test was conducted. Tables XI and XII show the means and the significance test results of factorial ANOVA tests. There is a moderately strong relationship between collaborative learning predisposition and social engagement, with an effect size of 0.26. As shown in Fig. 4, the least collaboratively oriented students had a greater increase in the level of social engagement compared to those who were most collaboratively oriented (i.e., the slope of the diamond line is more steep than the square line). In addition, the difference in social engagement between the two types of students was smaller in the collaborative exam than the traditional exam. However, the interaction effect is not significant. Therefore, H6 is not supported.

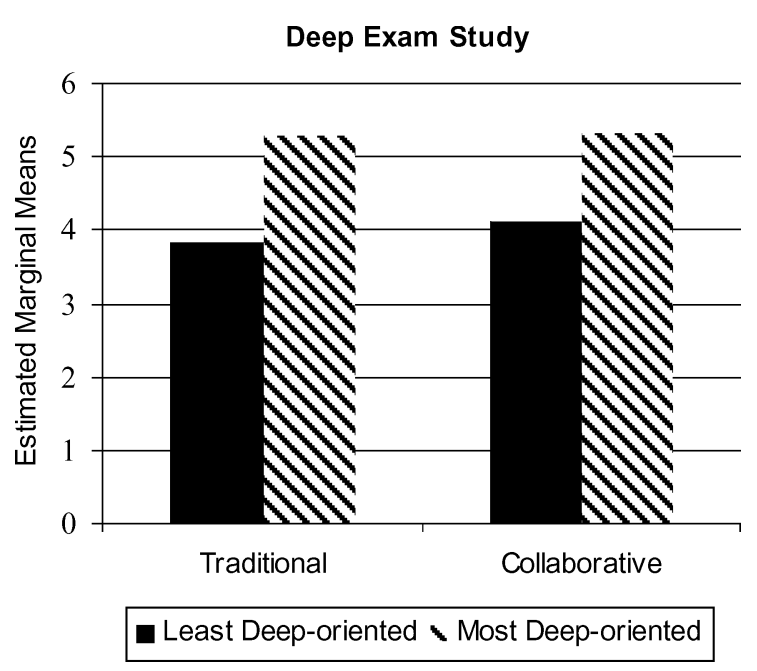

Fig. 3. Effects of learning predisposition and exam mode on deep exam study.

Table XI

SOCIAL ENGAGEMENT (EXAM MODE* PRE-EXAM COLlaborative LEARNING)

\begin{tabular}{c|c|c|c}
\hline \multicolumn{4}{c}{$\begin{array}{c}\text { Pre-exam Learning } \\
\text { Dispositions }\end{array}$} \\
$\begin{array}{c}\text { Least } \\
\text { ॠ }\end{array}$ & $\begin{array}{c}\text { Most } \\
\text { Le }\end{array}$ & $\begin{array}{c}\text { Collaboratively } \\
\text { Oriented }\end{array}$ & $\begin{array}{c}\text { Collaboratively } \\
\text { Oriented }\end{array}$ \\
\hline$T$ & $2.44(1.12)$ & $4.46(1.62)$ & $3.42(1.71)$ \\
\hline$C$ & $3.53(1.48)$ & $4.77(1.30)$ & $4.16(1.52)$ \\
\hline \multicolumn{1}{|c|}{ Total } & $2.99(1.42)$ & $4.62(1.46)$ & $3.80(1.65)$ \\
\hline$T:$ Traditional Exam; $C:$ Collaborative Exam.
\end{tabular}


To test hypotheses on student learning outcomes, one-way ANOVA tests were conducted on perceived learning and final exam/project grades. As mentioned before, final exam or project grades were collected and used as a measurement of students' actual learning in those courses where the experiment was conducted as the midterm exam and the final was a traditional exam. Final examinations or projects are comprehensive, covering the entire semester and not just the portion after the midterm; thus they include what was learned overall in the course. The ANOVA results are shown in Table XIII.

Significant differences were found among the three exam modes in perceived learning $(p<0.05)$, although the effect size is negligible (0.02). Post-hoc analysis reveals that students in the collaborative exam reported significantly higher perceptions of learning than those in the traditional exam

TABLE XII

FACTORIAL ANOVA FOR DATA IN TABLE XI

\begin{tabular}{|c|c|c|c|c|c|}
\hline 중 & \multicolumn{2}{|c|}{ Source } & $\boldsymbol{L}$ & 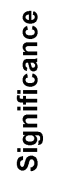 & 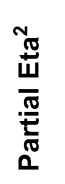 \\
\hline \multirow{3}{*}{$\begin{array}{l}\text { Social } \\
\text { Engage- } \\
\text { ment }\end{array}$} & $\begin{array}{l}\text { Main } \\
\text { Effect }\end{array}$ & $\begin{array}{l}\text { Exam Mode } \\
(1,3)\end{array}$ & 9.608 & .002 & .061 \\
\hline & $\begin{array}{l}\text { Main } \\
\text { Effect }\end{array}$ & $\begin{array}{l}\text { Pre-exam } \\
\text { Collaborative } \\
\text { Learning }\end{array}$ & 52.470 & .000 & .260 \\
\hline & $\begin{array}{l}\text { Interaction } \\
\text { Effect }\end{array}$ & $\begin{array}{l}\text { Exam Mode * } \\
\text { Pre-Collab }\end{array}$ & 2.960 & .087 & .0 \\
\hline
\end{tabular}

Social Engagement

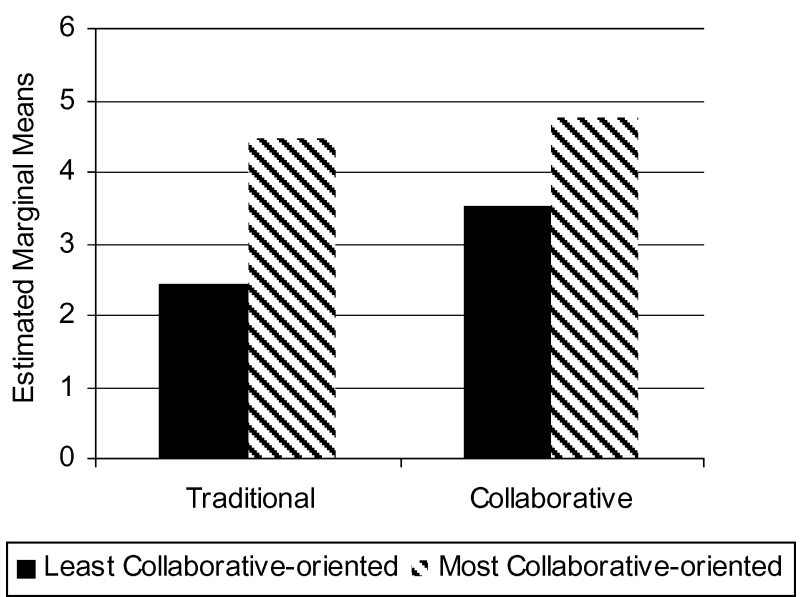

Fig. 4. Effects of learning predisposition and exam mode on social engagement. $(p<0.05)$. Therefore, H7.1 is supported, and H7.2 is not supported.

As shown in Table XIII, students in the collaborative exam achieved higher final exam/project grades than students in the other two exam modes. Using the final exam or project scores as the reflection of actual learning suggests that students in the collaborative online exam may have indeed learned the most from the midterm exam compared with the other two exams. However, the difference is not significant. Therefore, H8 is not supported.

To test H9, deep learning as measured in the post-exam survey was first categorized into low, medium, and high. The two extreme categories were used, and a $2 \times 2$ factorial ANOVA test was conducted. Tables XIV and XV show the means and the factorial ANOVA significance test results. As shown in Fig. 5, the interaction effect is not significant, even though the distance between the two lines is slightly smaller in the collaborative exam than the traditional exam. Therefore, H9 is not supported. It is notable that the effect size for the relationship between deep exam study strategy and perceived learning is substantial (0.326).

To test H10, social engagement as measured in the post-exam survey was first categorized into low, medium, and high. The two extreme categories were used and a $2 \times 2$ factorial ANOVA test was conducted. Tables XVI and XVII show the means and the factorial ANOVA significance test results. There is a moderate effect size for the relationship between social engagement and perceived learning, but no other relationship is significant. Fig. 6 shows that the least socially engaged have a drop in

TABLE XIII

LEARNING OUTCOMES (ANOVA TEST)

\begin{tabular}{|c|c|c|c|c|c|c|c|}
\hline 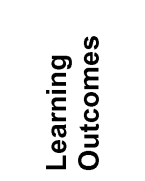 & $\begin{array}{l}\frac{0}{0} \\
\stackrel{0}{\Sigma} \\
\frac{1}{\pi} \\
\stackrel{x}{x}\end{array}$ & $\mathbf{z}$ & 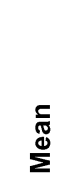 & os & ᄂ & 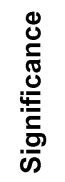 & 苗 \\
\hline \multirow{3}{*}{$\begin{array}{l}\text { Perceived } \\
\text { Learning }^{\text {a }}\end{array}$} & $T$ & 138 & 21.78 & 10.33 & \multirow{3}{*}{3.09} & \multirow{3}{*}{.047} & \multirow{3}{*}{.02} \\
\hline & $P$ & 109 & 23.91 & 10.04 & & & \\
\hline & C & 133 & 24.78 & 10.19 & & & \\
\hline \multirow{3}{*}{$\begin{array}{l}\text { Actual } \\
\text { Learning }^{b}\end{array}$} & $T$ & 129 & 78.41 & 16.38 & \multirow{3}{*}{1.03} & \multirow{3}{*}{.359} & \multirow{3}{*}{.01} \\
\hline & $P$ & 25 & 75.64 & 13.23 & & & \\
\hline & $C$ & 74 & 81.42 & 24.68 & & & \\
\hline
\end{tabular}

$T$ : Traditional Exam; $P$ : Participatory Exam;

$C$ : Collaborative Exam. ${ }^{a}=$ transformed scale.

${ }^{b}=$ final exam/project grade. 
perceived learning in the collaborative exam, while the most socially engaged stay almost the same in the two exams, but the interaction effect is not significant. Therefore, H1O is not supported.

The results are summarized in Fig. 7 , which is the research model shown in Fig. 1 with the results added. The numbers beside lines are

TABLE XIV

Perceived Learning (Exam Mode * Deep Exam Study)

\begin{tabular}{|c|c|c|c|}
\hline \multirow[b]{2}{*}{ 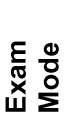 } & \multicolumn{2}{|c|}{ Study Strategy } & \multirow[b]{2}{*}{ Total } \\
\hline & $\begin{array}{l}\text { Least Deep } \\
\text { Learning }\end{array}$ & $\begin{array}{l}\text { Most Deep } \\
\text { Learning }\end{array}$ & \\
\hline$T$ & $16.23(8.44)$ & $29.22(8.91)$ & $21.02(10.63)$ \\
\hline C & $19.02(8.95)$ & $30.30(8.29)$ & $25.53(10.20)$ \\
\hline Total & $17.28(8.70)$ & $29.85(8.52)$ & $23.15(10.65)$ \\
\hline
\end{tabular}

TABLE XV

FACTORIAL ANOVA FOR DATA IN TABLE XIV

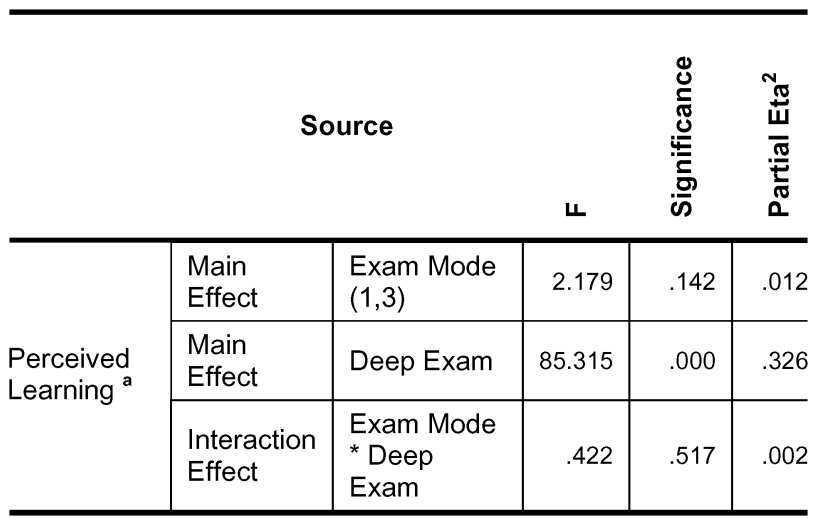

Perceived Learning

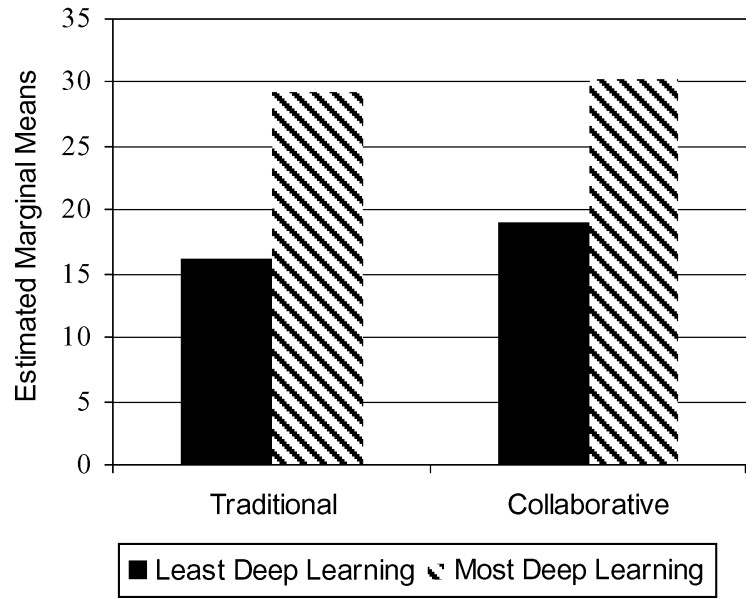

Fig. 5. Effects of deep exam study and exam mode on perceived learning. correlation coefficient Pearson's $R$ (indicated as $r$ ) or Spearman's rho. Significant differences found among the exams are highlighted with bold box outlines. Note that the two new constructs are added in the diagram, and the means for surface exam study are used in the diagram because the differences are significant.

TABLE XVI

Perceived Learning (Exam Mode * Social Engagement)

\begin{tabular}{|c|c|c|c|}
\hline \multirow{2}{*}{ 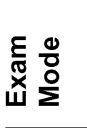 } & \multicolumn{2}{|c|}{ Study Strategy } & \multirow{2}{*}{ Total } \\
\hline & $\begin{array}{c}\text { Least Socially } \\
\text { Engaged }\end{array}$ & $\begin{array}{l}\text { Most Socially } \\
\text { Engaged }\end{array}$ & \\
\hline$T$ & $19.37(11.58)$ & $28.60(8.66)$ & $22.61(11.48)$ \\
\hline C & $15.87(14.92)$ & $29.33(8.20)$ & $26.04(11.70)$ \\
\hline Total & $18.48(12.51)$ & $29.08(8.32)$ & $24.25(11.68)$ \\
\hline
\end{tabular}

$T$ : Traditional Exam; $C$ : Collaborative Exam.

TABLE XVII

FACTORIAL ANOVA FOR DATA IN TABLE XVI

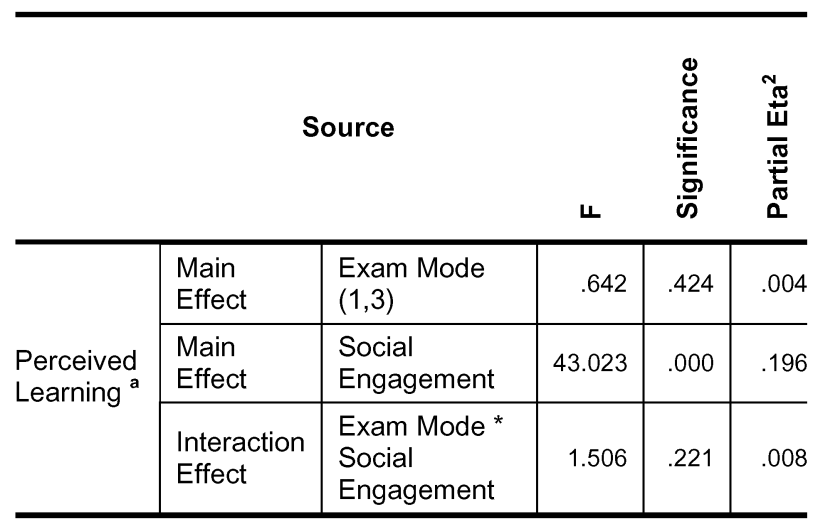

${ }^{a}=$ transformed scale.

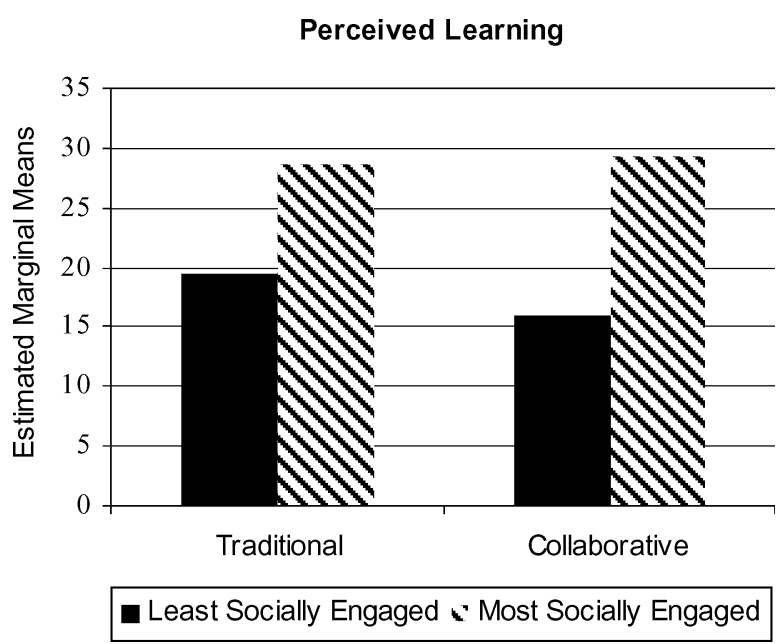

Fig. 6. Effects of social engagement and exam mode on perceived learning. 


\section{DISCUSSION}

This paper examines students' learning predispositions, adoption of exam study strategies, and learning outcomes when taking online exams. First, the results show that students' adoption of deep or surface exam study strategies were significantly associated with their deep or surface learning predispositions. More importantly, the participatory and collaborative online exams resulted in students adopting significantly lower levels of the surface exam study strategy. Students in the online exams reported significantly less use of memorization and rote learning without understanding the materials in exam study, compared with those in the traditional exam. As observed through the study, the online exams allowed students to prepare for the exams differently than for the traditional exam by motivating them to conduct in-depth research, cover a broader breadth of knowledge, and synthesize materials.

Second, the level of social engagement in exam study was not only significantly associated with students' predispositions in collaborative learning, but, more importantly, was significantly higher in the collaborative exam than both the participatory exam and the traditional exam. Students in the collaborative exam reported perceiving the exam process as a group experience, forming a sense of a learning community, and enhancing their understanding of course materials through interactions with other students. Strikingly, students' level of social engagement in the participatory online exam was significantly lower than that in the collaborative exam, and was at the same level as the traditional exam. This suggests

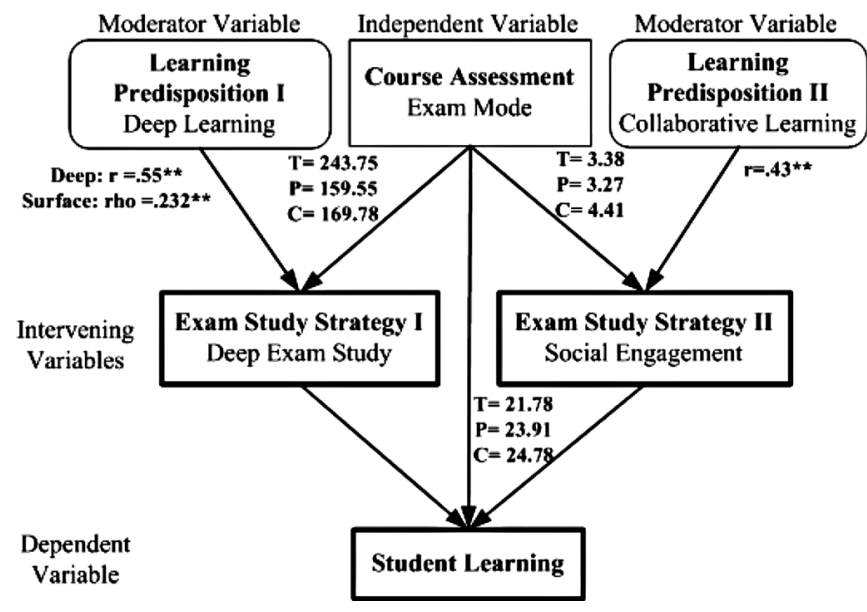

Fig. 7. Research model with results. that without incorporating the small group activities into the online process, the level of engagement in learning from others and the sense of a learning community are as low as in the traditional settings.

Significant differences were also found in student learning outcomes. Students in the collaborative exam reported significantly higher levels of perceived learning than those in the traditional exam. Students reported improvement in their understanding of course materials, and enhancement in skills such as using knowledge in new situations, solving problems, recognizing patterns, comparing ideas, and making judgments. As a measurement of actual learning, final exam/project grades were the highest among students who took the collaborative exam rather than the other two exam modes. Although the results were not significant, this suggests that students may indeed learn the most through the collaborative exam. Further studies are needed to investigate this, especially those based on longitudinal data.

While neither the interaction effects of the learning predispositions and exam modes on exam study strategies nor those of exam study strategies and exam modes on learning outcomes were statistically significant, they do provide some interesting indications that there may be an effect that is masked by sources of variance introduced by the field study design, in which many variables could not be controlled. The results using deep exam study indicate that the collaborative exam seemed to be the most effective in motivating the least deep-oriented students to adopt a higher level of deep exam study strategy. The collaborative exam also motivated the least collaborative-oriented students to adopt a higher level of social engagement than those who were most collaborative-oriented. In addition, there was a tendency towards a negative synergistic interaction effect, where the students who were least socially engaged in exam studying perceived less learning in the collaborative exam. The results suggest that the collaborative exam may be most effective in promoting deep learning and collaborative learning among those students who need to be motivated most, and this is important because students need to be actively engaged in group activities in order to achieve the most learning. This possibility should be pursued in a future study through refining exam and experimental procedures to focus on variables related to student motivation. 


\section{Conclusions}

This study contributes the first major investigation relating students' deep study and collaborative learning dispositions with their learning strategies for online collaborative exams. It also identifies and provides instruments for measuring learning strategies towards exam studying and learning outcomes.

Short of adopting the collaborative exam, what could instructors take away from this study to improve student study habits and overall learning? Even if students are predisposed to surface learning, they can be encouraged through structural changes involving collaboration and social engagement to adopt a deeper learning approach. This corroborates research by Tang [26], [27]. Incorporating peer review, as the collaborative exam does, leads to better preparedness. This corroborates research showing that when students know peers will read their assignments, it motivates learning [43], [44], which of course is our overall goal.

From a practical point of view, this research proposes an innovative form of online assessment that promotes teamwork skills and shifts the instructors' roles. Many university instructors feel the need to produce graduates with the skills desired by future employers (e.g., teamwork skills). Our study offers one way to incorporate teamwork into one of the most important learning activities: assessment in the online environment. This study shows that students' active engagement in teamwork is a significant mediator of students' learning outcomes. From the instructor's perspective, his or her role shifts from the designer and the grader to the facilitator of the exam. In addition, students' participation in the question design and grading phases make it possible to adopt question formats usually requiring more time in grading, such as essay questions or program coding questions. This reduces the constraints on the question types that can be used in collaborative testing without significantly impacting an instructor's workload. As the results show, students' perceived learning is significantly higher when they are involved in the whole exam process than in the traditional exams.

More generally, our results support the premise that when computer technology mediates and changes the form of interaction among participants in a process by moving it from physical space to cyberspace, then it can be beneficial to think about how all aspects of the process may be best adapted to fit the cyberspace environment. The various forms of "groupware" platforms that support threaded discussions and collaboration about the content of a course can also be adapted to support collaboration in the assessment process. The assessment process can become an integral part of the learning in the course, rather than a separate procedure completely divorced from it.

\section{ACKNOWLEDGMENT}

This work was supported in part by the Alfred P. Sloan Foundation; the United Parcel Service Foundation; the New Jersey Commission on Science and Technology through a grant to the New Jersey Center for Pervasive Information Technology; the National Science Foundation under Grant IIS-0135531, Grant DUE-0226075, Grant DUE-0434581, and Grant DUE-0434998; and the Institute for Museum and Library Services under Grant LG-02-04-0002-04. The authors gratefully acknowledge Dr. I. Im, Dr. K. Passerini, Dr. J. Scher, and Dr. D. Leidner for their valuable input and support for this research. Thanks to all the faculty members and students who participated in the experiments of this study. The opinions suggested are those of the authors and not necessarily those of the sponsors of this research.

\section{References}

[1] E. Allen and J. Seaman, Making the Grade: Online Education in the United States, 2006. Needham, MA: Sloan Consortium, 2006.

[2] M. Alavi and D. E. Leidner, "Research commentary: Technology-mediated learning-A call for greater depth and breadth of research," Inform. Syst. Res., vol. 12, no. 1, pp. 1-10, 2001.

[3] S. R. Hiltz and R. Goldman, Learning Together Online: Research on Asynchronous Learning Networks. Mahwah, NJ: Lawrence Erlbaum, 2004.

[4] R. Benbunan-Fich and S. R. Hiltz, "Mediators of the effectiveness of online courses," IEEE Trans. Prof. Commun., vol. 46, no. 4, pp. 298-312, Dec., 2003.

[5] D. E. Leidner and S. L. Jarvenpaa, "The use of information technology to enhance management school education: A theoretical view," MIS Quart., vol. 19, no. 3, pp. 265-291, 1995.

[6] L. S. Vygotsky, Mind in Society: The Development of Higher Psychological Processes. Cambridge, MA: Harvard Univ. Press, 1978.

[7] J. Hawkins and R. Pea, "Tools for bridging everyday and scientific thinking," J. Res. Sci. Teaching, vol. 24, no. 4, pp. 291-307, 1987. 
[8] M. E. Huba and J. E. Freed, Learner-Centered Assessment on College Campuses: Shifting the Focus From Teaching to Learning, 1st ed. Needham Heights, MA: Pearson Allyn \& Bacon, 1999.

[9] T. A. Angelo and K. P. Cross, Assessment Techniques: A Handbook for College Teachers, 2nd ed. San Francisco, CA: Jossey-Bass, 1993.

[10] L. Vygotsky, Thought and Language. Cambridge, MA: MIT Press, 1962.

[11] M. Alavi and D. Dufner, "Technology-mediated collaborative learning: A research perspective," in Learning Together Online: Research on Asynchronous Learning Networks, S. R. Hiltz and R. Goldman, Eds. Mahwah, NJ: Lawrence Erlbaum, 2004.

[12] R. C. W. Kwok and J. Ma, "Use of a group support system for collaborative assessment," Computers \& Education, vol. 32, no. 2, pp. 109-125, 1999.

[13] E. V. Wilson, "Examnet asynchronous learning network: Augmenting face-to-face course with student-developed exam questions," Comput. Edu., vol. 42, no. 1, pp. 87-107, 2004.

[14] J. Shindler, "Examining the soundness of collaborative essay exams in teacher education courses," Nat. Forum Teacher Edu. J., vol. 12, no. 3, p. 25, 2002.

[15] J. V. Shindler, "Greater than the sum of the parts? Examining the soundness of collaborative exams in teacher education courses," Innovative Higher Edu., vol. 28, no. 4, p. 273, 2004.

[16] M. G. Simkin, "An experimental study of the effectiveness of collaborative testing in an entry-level computer programming class," $J$. Inform. Syst. Edu., vol. 16, no. 3, pp. 273-280, 2005.

[17] N. Falchikov and J. Goldfinch, "Student peer assessment in higher education: A meta-analysis comparing peer and teacher marks," Rev. Educational Res., vol. 70, pp. 287-322, 2000.

[18] D. M. A. Sluijsmans, S. Brand-Gruwel, J. Van Merriënboer, and T. R. Bastiaens, "The training of peer assessment skills to promote the development of reflection skills in teacher education," Stud. Educational Evaluation, vol. 29, no. 1, pp. 23-42, 2003.

[19] K. J. Topping, "Peer assessment between students in college and university," Rev. Edu. Res., vol. 68, no. 3, pp. 249-276, 1998.

[20] J. Shen, M. Bieber, and S. R. Hiltz, "Participatory examinations in asynchronous learning networks: Longitudinal evaluation results," J. Asynchronous Learning Networks, vol. 9, no. 3, pp. 93-113, 2005.

[21] J. Shen, S. R. Hiltz, K. E. Cheng, Y. Cho, and M. Bieber, "Collaborative examinations for asynchronous learning networks: Evaluation results," in Proc. 34th Hawaii Int. Conf. Systems Sciences, 2001, pp. 1-10.

[22] N. Entwistle, "Promoting deep learning through teaching and assessment," in Proc. AAHE's 2000 Assessment Conf.: Rising Expectations for Assessment, 2000, pp. 9-20.

[23] C. Gordon and R. Debus, "Developing deep learning approaches and personal teaching efficacy within a preservice teacher education context," Brit. J. Educational Psychology, vol. 72, pp. 483-511, 2002.
[24] J. B. Biggs, Student Approaches to Learning and Studying. Camberwell, Victoria: Australian Council for Educational Research, 1987.

[25] F. Marton and R. Saljo, "On qualitative differences in learning, outcome and process," Brit. J. Educational Psychology, vol. 46, no. 1, pp. 4-11, 1976.

[26] C. Tang, "Effects of different assessment procedures on tertiary students' approaches to studying," Ph.D. thesis, University of Hong Kong, Hong Kong, 1991.

[27] C. Tang, "Effects of modes of assessment on students' preparation strategies," in Improving Student Learning - Theory and Practice, G. Gibbs, Ed. Oxford: Oxford Center for Staff Development, 1994, pp. 10-15.

[28] L. Suchman, Plans and Situated Actions. Cambridge, UK: Cambridge Univ. Press, 1987.

[29] E. Hutchins, Cognition in the Wild. Cambridge, MA: MIT Press, 1995.

[30] E. Wenger, Communities of Practice: Learning, Meaning, and Identity. New York: Cambridge Univ. Press, 1998.

[31] C. Gunawardena and F. Zittle, "Social presence as a predictor of satisfaction within a computer mediated conferencing environment," Amer. J. Distance Learning, vol. 11, no. 3, pp. 8-26, 1997.

[32] J. Richardson and K. Swan, "An examination of social presence in online learning: Students' perceived learning and satisfaction," $J$. Asynchronous Learning Networks, vol. 7, no. 1, pp. 68-88, 2003.

[33] A. G. Picciano, "Beyond student perceptions: Issues of interaction, presence, and performance in an online course," J. Asynchronous Learning Networks, vol. 6, no. 1, pp. 21-40, 2002.

[34] J. Shen, "Collaborative Examinations in Asynchronous Learning Networks: Field Experiments on Collaborative Learning Through Online Assessments," Ph.D. thesis, Department of Information Systems, New Jersey Institute of Technology, Newark, 2005.

[35] R. Benbunan-Fich, S. R. Hiltz, and L. Harasim, "The online interaction learning model: An integrated theoretical framework for learning networks," in Learning Together Online: Research on Asynchronous Learning Networks, S. R. Hiltz and R. Goldman, Eds. Mahwah, NJ: Lawrence Erlbaum, 2004, pp. 19-38.

[36] S. R. Hiltz and P. J. Shea, "The student in the online classroom," in Learning Together Online: Research on Asynchronous Learning Networks, S. R. Hiltz and R. Goldman, Eds. Mahwah, NJ: Lawrence Erlbaum, 2004, pp. 145-168.

[37] J. B. B. Arbaugh and R. Benbunan-Fich, "Contextual factors that influence ALN effectiveness," in Learning Together Online: Research on Asynchronous Learning Networks, S. R. Hiltz and R. Goldman, Eds. Mahwah, NJ: Lawrence Erlbaum, 2004, pp. 123-144.

[38] B. Bloom, A Taxonomy of Educational Objectives: The Classification of Educational Goals. New York: D. McKay Co., 1956.

[39] J. Shen, K. E. Cheng, Y. Cho, S. R. Hiltz, and M. Bieber, "Evaluation of an on-line collaborative examination process," in Proc. Americas Conf. Information Systems, CA, 2000, pp. 1791-1797. 
[40] J. Shen, K. E. Cheng, M. Bieber, and S. R. Hiltz, "Traditional in-class examination vs. collaborative online examination in asynchronous learning networks: Field evaluation results," in Proc. Americas Conf. Information Systems, 2004, pp. $1-10$.

[41] D. Wu, M. Bieber, S. R. Hiltz, and H. Han, "Constructivist learning with participatory examinations," in Proc. HICSS 37th Hawaii Int. Conf. Systems Sciences, 2004, pp. 12-20.

[42] J. Biggs, D. Kember, and D. Y. P. Leung, “The revised two-factor study process questionnaire: R-Spq-2f,” Brit. J. Educational Psychology, vol. 71, no. 1, pp. 133-149, 2001.

[43] K. Cho and C. D. Schunn, "Scaffolded writing and rewriting in the discipline: A web-based reciprocal peer review system," Comput. Edu., vol. 48, no. 3, pp. 409-426, 2005.

[44] D. McConnell, "Examining collaborative assessment processes in networked lifelong learning," J. Comput. Assisted Learning, vol. 15, no. 3, pp. 232-243, 1999.

Jia Shen received the Ph.D. degree in information systems from New Jersey Institute of Technology (NJIT) in 2005. She is an Assistant Professor in the College of Business Administration, Rider University, Lawrenceville, NJ. She has published in IEEE TRANSACTIONS, the Journal of Asynchronous Learning Networks, and presented at many conferences in information systems.
Her research interests include human-computer interactions, E-Commerce, online learning, and virtual teamwork.

Starr Roxanne Hiltz received the Ph.D. degree from Columbia University in 1969. She is Distinguished Professor Emerita, College of Computing Sciences, New Jersey Institute of Technology, Newark. A sociologist by training, she has spent most of the last 30 years engaged in research on applications and social impacts of computer technology, publishing widely in journals including JMIS, Communications of the ACM, and IEEE TRANSACTIONS. Her research interests currently include group support systems, asynchronous learning networks, pervasive computing, and emergency response information systems. Her most recent book, co-edited with Ricki Goldman, is Learning Together Online: Research on Asynchronous Learning Networks (Erlbaum, 2005).

Michael Bieber received the Ph.D. degree in decision sciences from the University of Pennsylvania in 1990. He currently is a Professor in the Information Systems Department of the College of Computing Sciences, New Jersey Institute of Technology, Newark. He is conducting research in several related areas: participatory learning, hypermedia functionality, automatically generating links and services for web applications and for digital libraries, relationship analysis (as part of the software engineering process), and virtual communities. Prof. Bieber is a member of the Association of Information Systems and ACM SIGWEB. 